\title{
EL CONTROL DE LA LEGALIDAD DE LAS ORDENANZAS MUNICIPALES: CRITERIOS Y PROPUESTAS
}

\author{
CONTROL OF THE LEGALITY OF MUNICIPAL \\ ORDINANCES: CRITERIA AND PROPOSALS
}

\begin{tabular}{|c|c|}
\hline \multicolumn{2}{|c|}{ ARTÍCULO INÉDITO DE INVESTIGACIÓN } \\
\hline CÓMO CITAR ESTE ARTÍCULO (CHICAGO) & 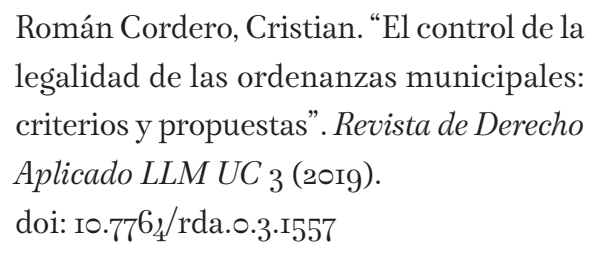 \\
\hline REVISTA DE DERECHO APLICADO LLM UC & $\begin{array}{l}\text { Número } 3 \\
\text { Julio } 20 \text { I9 } \\
\text { ISSN: } 245^{2-} 4344\end{array}$ \\
\hline & $\begin{array}{l}\text { Recepción: I3 de junio, } 20 \text { I9 } \\
\text { Aceptación: I de julio, } 20 \text { I9 }\end{array}$ \\
\hline
\end{tabular}




\section{Resumen}

El presente trabajo estudia las ordenanzas municipales, sus características, sus formas de control ex ante y ex post, y criterios de control establecidos por la jurisprudencia constitucional, judicial y administrativa. Propone mejorar el control ex ante de las ordenanzas municipales, ya que actualmente ellas son una creciente amenaza para los derechos fundamentales.

Palabras clave: ordenanzas, municipalidades, control, legalidad, constitucionalidad.

\section{Abstract}

This paper studies municipal ordinances, their characteristics, their forms of ex ante and ex post control, and control criteria established by constitutional, judicial and administrative jurisprudence. It proposes to improve the ex ante control of municipal ordinances, since they are currently a growing threat to fundamental rights.

Keywords: ordinances, municipalities, control, legality, constitutionality 


\section{Cristian Román Cordero}

Universidad de Chile

Facultad de Derecho

Santiago, Chile

croman@derecho.uchile.cl

Universidad de Chile

Faculty of Law

Santiago, Chile

croman@derecho.uchile.cl
Cristian Román Cordero es abogado de la Universidad de Chile y profesor de Derecho Administrativo de la Facultad de Derecho de la Universidad de Chile.

Cristian Román Cordero is a lawyer from the Universidad de Chile and Professor of Administrative Law at the Faculty of Law of the Universidad de Chile. 
"Les pouvois constitutionnels son : le pouvoir royal, le pouvoir exécutif, le pouvoir representatif, le pouvoir judiciaire et le pouvoir municipal". Constant, Cours de politique constitutionelle, Didier Libraire-Editeur, Paris, 1836, citado por García Fernández, Javier, El origen del municipio constitucional, Instituto de Estudios de la Administración Local, Madrid, 1983, p. 92.

\section{Introducción}

Tal como dan cuenta las reiteradas notas de prensa del último tiempo, pareciera que hoy dictar ordenanzas municipales está de moda. Ello se explica por múltiples razones: la búsqueda de exposición mediática por parte de algunos alcaldes; poner temas de discusión a nivel local, regional o nacional; corregir o resolver a través de ellas algunos problemas locales; reglar el ejercicio de ciertas potestades municipales (del alcalde, o del alcalde con acuerdo del concejo); etcétera.

Mas lo cierto es que las ordenanzas municipales se han desbocado tanto por las materias que están reglando como por la intensidad de la reglamentación que contienen (especialmente cuando ésta se presenta en forma de limitaciones, restricciones y prohibiciones). Por ello es que en no pocas oportunidades -más de las que quisiéramos, por cierto- ellas están excediendo los límites que importan, entre otros, sus funciones y atribuciones, y nuestros derechos fundamentales.

En efecto, las ordenanzas municipales están exentas del trámite de la toma de razón. Así, su control preventivo recae en el alcalde y concejo a quienes corresponde aprobarlas, como también en la Unidad de Control de la propia municipalidad. Mientras que en los primeros se evidencia un marcado voluntarismo en orden a aprobarlas, a pesar de los vicios de inconstitucionalidad o ilegalidad que pudieran tener, la segunda no tiene la solidez institucional para contrarrestarlo, por más patentes que sean dichos vicios. De esta forma parece primar lo "bueno" de la ordenanza municipal por sobre esos vicios, quizás acaso con la consideración de que su infracción sólo dará origen a una multa menor para el infractor -misma cuya imposición se sujeta a un procedimiento jurisdiccional-, y que si es preciso corregir algo de ella, eso se hará "en el camino", una vez que ésta haya entrado en vigor.

Es así como una constante actual es que las ordenanzas municipales están reglando materias propias de ley y, además, estableciendo restricciones a derechos fundamentales, que incluso en no pocas oportunidades han afectado su contenido esencial, sin que hayan sido sometidas a un control preventivo de legalidad en concordancia con estas nuevas ordenanzas municipales (las que llamaremos “ordenanzas 2.0”). 
Y esto es muy paradójico si se considera que si el contenido de algunas de estas ordenanzas se hallara en una ley o reglamento (de ejecución o autónomo) no verían la luz, por cuanto a su respecto habrían operado correcta y oportunamente los controles preventivos de constitucionalidad y/o legalidad, según el caso. Y si bien las sanciones que pueden imponerse por infracción a las ordenanzas son menores (de multa, hasta 5 unidades tributarias mensuales), el solo hecho que ellas hayan entrado en vigor con tales vicios, incorporándose así al Ordenamiento Jurídico, constituye, a nuestro juicio, un grave atentado al Estado de Derecho, que preciso es oportunamente evitar o corregir.

Por todo ello, constituye hoy una acuciante necesidad estudiar los límites de las ordenanzas municipales y su control, especialmente el preventivo, lo que haremos a continuación.

\section{Aspectos generales de las ordenanzas municipales}

\section{(A). Concepto, características y procedimiento de creación de las ordenanzas municipales}

Las ordenanzas municipales son, en primer lugar, fuentes del Derecho Administrativo. Ello importa:

(i). Que son vinculantes tanto para la propia municipalidad que las ha dictado como para la respectiva comunidad. Así, por ejemplo, una municipalidad debe emplear los mecanismos de participación ciudadana que contempla su propia ordenanza de participación ${ }^{1}$; debe cumplir el deber de fiscalización que sus propias ordenanzas le fijan (por ejemplo, en materia de ruidos) ${ }^{2}$; y el alcalde, al otorgar permisos de ocupación de bien nacional de uso público, conformarse al procedimiento que le fija su respectiva ordenanza ${ }^{3}$; todo ello pues las municipalidades deben conformarse al Ordenamiento Jurídico, «el que se encuentra

1 Así, la Contraloría General de la República, en el dictamen $\mathrm{N}^{\circ} 2.4_{4}^{8} 4_{-20 \mathrm{I}}$, sostuvo que "la aludida convocatoria a un mecanismo de participación ciudadana en la comuna de Freirina, infringió, en los términos expuestos, las exigencias previstas en la citada ordenanza municipal, de forma tal que, en lo sucesivo, ese municipio deberá observar estrictamente la normativa que regula la aplicación de tales instrumentos”.

2 Así la Corte Suprema, en la sentencia Rol No I8.846-20I8, sostuvo que, "del modo en que se viene reflexionando, aparece que la Municipalidad de Santiago cumplió con el deber de fiscalización contemplado en el inciso tercero del artículo $5^{\circ}$ de la Ley $\mathrm{N}^{\mathrm{o}}$ i8.695 y en el artículo in de la Ordenanza Nº 80, de 1998 ".

3 Así, la Contraloría General de la República, en el dictamen $N^{0} 3^{2.889-20 I I, ~ s o s t u v o ~ q u e ~ " e s ~}$ dable manifestar que los alcaldes al otorgar permisos para ejercer el comercio en la vía pública deben dar cumplimiento a las normas que en relación con la materia se contengan en las correspondientes ordenanzas municipales". 
integrado, a nivel local, por las ordenanzas que el mismo municipio haya aprobado»"; y

(ii). Que su contenido es general y abstracto, circunscrito al ámbito local. Así las ordenanzas municipales no pueden contener excepciones singulares ni la propia municipalidad dictar decretos alcaldicios que las establezcan (no caben, por tanto, derogaciones singulares de ordenanzas municipales). Así, por ejemplo, respecto de la ordenanza de derechos municipales, no es admisible que, a través de un decreto alcaldicio, se establezcan exenciones o rebajas singulares.

En este orden de cosas, las ordenanzas municipales son manifestación de la potestad normativa de las municipalidades, misma que si bien le reconoce expresamente la Constitución ${ }^{5}$, debe entenderse implícita en atención a que ellas son por esencia autónomas ${ }^{6}$. En este contexto, la Ley N ${ }^{\circ}$ 18.695, Orgánica Constitucional de Municipalidades, las define como «normas generales y obligatorias aplicables a la comunidad. En ellas podrán establecerse multas para los infractores, cuyo monto no excederá de cinco unidades tributarias mensuales, las que serán aplicadas por los juzgados de policía local correspondientes» .

Las ordenanzas municipales se sitúan jerárquicamente bajo la Constitución, las leyes y los reglamentos, debiendo conformarse a todos ellos. Así el principio de legalidad al que ellas están afectas se refiere no sólo a la ley, sino que al bloque de legalidad, razón por la cual es más preciso denominarlo derechamente principio de juridicidad. En este contexto, cabe destacar que las ordenanzas municipales sólo pueden ser dictadas por municipalidades ${ }^{8}$, y que ellas pueden regular materias que la ley les señala expresamente ${ }^{9}$, y cualquier otra con tal que estén comprendidas dentro de las funciones y atribuciones que la Ley $\mathrm{N}^{0}$

4 Dictamen de la Contraloría General de la República Nº $3^{2.889-20 I I . ~}$

5 Artículo irg, inciso $2^{\circ}$, de la Constitución Política de la República.

6 Sentencia del Tribunal Constitucional Rol No 80 , considerando $5^{\circ}$.

7 Artículo I2, inciso $2^{\circ}$, de la Ley N ${ }^{0}$ I8.695, Orgánica Constitucional de Municipalidades.

8 Hago esta precisión pues los Gobiernos Regionales tienen una potestad análoga, en cuya virtud pueden "dictar normas de carácter general para regular las materias de su competencia, con sujeción a las disposiciones legales y a los decretos supremos reglamentarios, las que estarán sujetas al trámite de toma de razón por parte de la Contraloría General de la República y se publicarán en el Diario Oficial”, conforme a lo previsto en el artículo i6, letra h), de la Ley No I9.I75, Orgánica Constitucional Sobre Gobierno y Administración Regional.

9 Por ejemplo: la ordenanza de participación de la ciudadanía local (artículo 93 de la Ley $\mathrm{N}^{\circ}$ I8.695, Orgánica Constitucional de Municipalidades); la ordenanza de plano regulador comunal (artículo 24, letra a), de la Ley No I8.695, Orgánica Constitucional de Municipalidades); la ordenanza ambiental (artículo 25, letra f), de la Ley No 18.695 , Orgánica Constitucional de Municipalidades); la ordenanza sobre horarios de funcionamiento de los locales de expendio de 
18.695, Orgánica Constitucional de Municipalidades, les otorga en sus artículos $3^{\circ}, 4^{\circ}$ y $5^{\circ}$. Así es posible distinguir entre las ordenanzas municipales "de ejecución", que concretan el mandato general y abstracto de la ley en el ámbito local, y las "autónomas", que sin ser de aquéllas, introducen innovaciones al Ordenamiento Jurídico ${ }^{10}$.

En cuanto al procedimiento de creación de ordenanzas municipales, cabe señalar:

(i). Las ordenanzas municipales deben ser aprobadas por el alcalde con acuerdo del concejo $^{11}$. En este contexto, la iniciativa corresponde exclusivamente al primero, en tanto máxima autoridad municipal.

(ii). Si bien ningún precepto legal dispone en forma explícita que en el procedimiento de creación de una ordenanza municipal deben aplicarse mecanismos de participación ciudadana, estimamos que, por la creciente relevancia que éstas tienen, ello es muy conveniente a fin de obtener una mejor normativa (ya que permitirá apreciar ex ante sus posibles efectos adversos) y que ésta cuente con una mayor legitimación democrática.

En este contexto, parece conveniente que en la respectiva ordenanza municipal de participación ${ }^{12}$ se establezca algún mecanismo de participación, con el carácter de obligatorio, en el procedimiento de creación de otras ordenanzas. Con todo, la Contraloría General de la República desaprueba esto, pues ha planteado que la potestad para dictar estas ordenanzas es propia de las municipalidades, «por lo que no resulta pertinente establecer obligatoriamente la mencionada consulta (en la ordenanza de participación -nota nuestra-), pues ello introduciría trámites y requisitos adicionales no contemplados en la legislación. Lo anterior no obsta, en todo caso, a que si la autoridad así lo dispone, se efectúen esas consultas a la comunidad durante la tramitación de esas ordenanzas» ${ }^{13}$.

En todo caso, cabe destacar que si una municipalidad, durante el procedimiento de creación de una ordenanza municipal, emplea alguno de estos mecanismos de participación

alcohol (artículo 65, letra o), de la Ley No 18.695 , Orgánica Constitucional de Municipalidades), la ordenanza sobre cierre o medidas de control de calles o pasajes (artículo 65, letra q), de la Ley N N I8.695, Orgánica Constitucional de Municipalidades), y la ordenanza sobre la tenencia responsable de mascotas o animales de compañía en el territorio comunal (artículo $7^{\circ}$ de la Ley $\mathrm{N}^{0}$ 2I.020, sobre Tenencia Responsable de Mascotas y Animales de Compañía -conocida coloquialmente como "Ley Cholito"-).

10 Sentencia del Tribunal Constitucional Rol No ${ }^{\circ} \cdot 669$, considerando $47^{\circ}$.

11 Artículo 65, letra k), de la Ley No I8.695, Orgánica Constitucional de Municipalidades.

12 Artículo 93 de la Ley No 18.695 , Orgánica Constitucional de Municipalidades.

13 Dictamen de la Contraloría General de la República Nº I6.5०6-20I8. 
(por ejemplo, una consulta pública), de cuyo resultado se concluye que ésta cuenta con un amplio y decidido apoyo ciudadano, ello en lo absoluto sanea los vicios de inconstitucionalidad o ilegalidad que pudiera tener ${ }^{14}$.

(iii). Las ordenanzas municipales no deben contenerse en un decreto alcaldicio. Ello, pues, conforme ha señalado la Contraloría General de la República, a la luz del artículo 12 de la Ley No 18.695, Orgánica Constitucional de Municipalidades, ambas resoluciones municipales «tienen naturalezas distintas, por lo que no ha correspondido que dicha entidad edilicia haya procedido a aprobar mediante decreto alcaldicio acto administrativo reservado para cierto tipo de actuaciones una resolución municipal que tiene el carácter de ordenanza, como ocurre en la especie $»^{15}$. Con todo, no podemos dejar de observar que es una práctica habitual de nuestras municipalidades.

Lo anterior tiene relevancia en relación al control de las ordenanzas (especialmente represivo), en cuanto a su arbitrariedad. En efecto, si una ordenanza municipal se contiene en un decreto alcaldicio, y éste no la motiva, esto no importa una infracción al deber de motivación de los actos administrativos ${ }^{16}$, pues al ser la ordenanza municipal una resolución distinta, basta con que su motivación conste en las actas de la sesión del concejo en la que fue aprobada ${ }^{17}$.

(iv). Las ordenanzas municipales entran en vigor una vez que han sido publicadas, salvo éstas dispongan otra oportunidad. Dicha publicación debe efectuarse «en los sistemas

14 Por ejemplo, el alcalde de la I. Municipalidad de Las Condes tuvo la idea de establecer, mediante una ordenanza municipal, un "toque de queda" respecto de menores de 16 años en cierto tramo horario nocturno. Dicha idea fue sometida a consulta pública, ganando la opción "sí" (no obstante ello, el alcalde decidió finalmente no concretar dicha medida a través de una ordenanza municipal). Pues bien, dicha "aprobación" ciudadana en caso alguno habría saneado los evidentes vicios de inconstitucionalidad e ilegalidad que dicha ordenanza, de haber sido aprobada y entrado en vigor, habría tenido.

Cf.: "Ganó el "sí". Se impone el toque de queda infantil en consulta impulsada por Lavín que tuvo menos de $10 \%$ de participación", en "elmostrador.cl”.

Link: https://www.elmostrador.cl/destacado/20I9/o6/3o/gano-el-si-se-impone-el-toque-dequeda-infantil-en-consulta-impulsada-por-lavin-que-tuvo-menos-de-Io-de-participacion/

15 Dictamen de la Contraloría General de la República $\mathrm{N}^{\mathrm{o}}$ I7.I88-20I. . En el mismo sentido, los dictámenes Nº 7.329-20I8, 70.127-2014 y 75:366-20I3.

16 Artículo ir de la Ley No ${ }^{\circ}$ 9.880, sobre Bases de los Procedimientos Administrativos.

17 Sentencias de la Corte de Apelaciones de Santiago Rol N ${ }^{\circ}$ I9I-20I8 y de la Corte de Apelaciones de Antofagasta Rol Nº 2.988-2017. 
electrónicos o digitales de que disponga la municipalidad» ${ }^{18}$, y no en el Diario Oficial ${ }^{19}$.

(v). Las ordenanzas municipales, como la generalidad de las resoluciones municipales, están exentas por ley del trámite de toma de razón ${ }^{20}$. De esta forma, el control preventivo de legalidad de éstas corresponde al alcalde y al concejo ${ }^{21}$, y a la Unidad de Control municipal ${ }^{22}$. A esto nos referiremos más adelante.

\section{(B). Rol de las ordenanzas municipales en el sistema de fuentes del Derecho Adminis-} trativo

Históricamente, las ordenanzas municipales han servido un rol muy menor en el sistema de fuentes del Derecho Administrativo. Prácticamente, irrelevante. Basta al efecto tan sólo revisar las materias abordadas por las ordenanzas municipales de la década pasada ${ }^{23}$. Mas en el último tiempo, especialmente en el último lustro, éstas han adquirido una singular relevancia tanto cuantitativa como cualitativa. Esto se evidencia en el hecho que en no pocos casos las materias que abordan son propias de otras fuentes normativas (ley o reglamento por el carácter nacional, y no local) y se refieren a derechos fundamentales

18 Artículo 12, inciso final, de la Ley No 18.695 , Orgánica Constitucional de Municipalidades. Cabe destacar que esto está en correspondencia con lo preceptuado en el artículo $7^{\circ}$, letra c), de la Ley $\mathrm{N}^{\mathrm{o}} 20.285$, sobre Transparencia. Así, la Contraloría General de la República, en su dictamen $\mathrm{N}^{\mathrm{o}} 60.748$-20II, sostuvo que "a partir de la vigencia del actual inciso final del citado artículo ı2, los reglamentos y ordenanzas municipales por los que se consulta pueden ser válidamente difundidos en la página web de los municipios, no siendo actualmente necesaria su publicación en el Diario Oficial". En el mismo sentido, cf.: dictamen $\mathrm{N}^{\circ} 26.0 \mathrm{r} 9-20 \mathrm{I}$ y sentencia de la Corte Suprema Rol No $5 \cdot 379^{-2012 .}$

19 La Contraloría General de la República, antes de la entrada en vigor de la Ley $\mathrm{N}^{0}{ }_{20.28}$, sobre Transparencia, entendió que la publicación debía efectuarse en el Diario Oficial, por aplicación supletoria de lo dispuesto por el artículo 48 de la Ley $\mathrm{N}^{\circ}$ I9.880, sobre Bases de los Procedimientos Administrativos. En este sentido, Cf.: el dictamen de la Contraloría General de la República Nº 7.902-2009.

20 Artículo 53 de la Ley Nº 18.695 , Orgánica Constitucional de Municipalidades.

21 Artículos 65, letra k), de la Ley No 18.695 , Orgánica Constitucional de Municipalidades, y II, inciso $2^{\circ}$, de la Ley N ${ }^{\mathrm{o}}$ I8.575, Orgánica Constitucional de Bases Generales de la Administración del Estado.

22

Artículo 29, letra c), de la Ley No I8.695, Orgánica Constitucional de Municipalidades.

23 Al respecto, Cf.: "Las leyes municipales que casi nadie entiende", en "latercera.cl".

Link: http:/www.latercera.com/noticia/nacional/20I4/o8/680-589608-9-las-leyes-municipalesque-casi-nadie-entiende.shtml 
(introduciendo incluso restricciones a éstos que afectan su contenido esencial -lo cual es propio y exclusivo de la ley $\mathrm{y}^{24}$-). Estas son las que hemos denominado "ordenanzas 2.0".

Lo anterior, además, se constata en la jurisprudencia del Tribunal Constitucional, ya que éste ha comenzado a pronunciarse al respecto a propósito del control preventivo de constitucionalidad de la ley ${ }^{25} \mathrm{y}$ de la inaplicabilidad. De esta última forma, en casos en los cuales se ha requerido la inaplicación del artículo 12 de la Ley No 18.695 , Orgánica Constitucional de Municipalidades, que otorga a éstas la potestad para dictarlas ${ }^{26}$, y en otros, en los que erradamente se ha requerido la inaplicación de parte del articulado de algunas ordenanzas municipales, mismos que dicha Magistratura ha declarado inadmisibles por no impugnar un precepto legal como es lo propio de esta acción constitucional ${ }^{27}$.

En este contexto, dicha Magistratura ha observado que las ordenanzas municipales tienen un rol prioritario en el sistema de fuentes del Derecho Administrativo, al señalar que ellas son manifestación de una "potestad reglamentaria municipal", la que se asemeja a la potestad reglamentaria del Presidente de la República (aunque subordinada a ésta ${ }^{28}$ ), y que ellas concretan (especialmente si son "de ejecución") el mandato general y abstracto de la ley en el plano local (en tanto que el reglamento hace lo propio en el plano nacional).

Es así como la sentencia del Tribunal Constitucional Rol No 1.669 sostuvo:

Que, tratándose de la potestad reglamentaria municipal, sin embargo, es necesario considerar que tiene que existir un espacio para los intereses municipales en la complementación o ejecución de la legislación. En ese sentido, la ley debe regular nacionalmente, pero con una uniformidad básica o esencial. El elemento normativo uniforme o común del legislador nacional debe ser, por lo mismo, no especialmente detallado. Por una parte, porque no puede no considerar las realidades diferentes de cada municipio. Las casi 350 municipalidades que existen en nuestro país, no son iguales. Tienen diferencias geográficas, de clima, de realidad económica, de densidad poblacional. Por la otra, porque el municipio cuenta con órganos representativos de los intereses comunes en su estructura organizativa (el Concejo Municipal, el alcalde). Ellos deben diseñar y aprobar las normas cuyos destinatarios son los habitantes de la comuna. Llevar la legislación a sus consecuencias prácticas, no puede prescindir de la realidad local ${ }^{29}$.

24. Artículo ig $\mathrm{N}^{\mathrm{o}} 26$ de la Constitución Política de la República.

25 Sentencia del Tribunal Constitucional Rol No $3 \cdot 489$ (prevención de los ministros señor Aróstica, señora Brahm y señor Letelier, considerando $\left.4_{4}^{\circ}\right)$.

26 Sentencia del Tribunal Constitucional Rol N ${ }^{\circ}$ I.669, considerando $56^{\circ}$.

27 Por ejemplo, Cf.: las sentencias del Tribunal Constitucional Roles Nºs I.268 y I.457.

28 Sentencia del Tribunal Constitucional Rol $N^{\circ} 2.899$, considerando II $^{\circ}$.

29 Sentencia del Tribunal Constitucional Rol N ${ }^{\circ}$ I.669, considerando $5^{6^{\circ}}$. 
En tanto que su sentencia Rol No 3.063 planteó que la potestad de las municipalidades conforme a la cual pueden dictar ordenanzas municipales «se asemeja a la potestad reglamentaria de ejecución del Presidente de la República, que establece el artículo $32, \mathrm{~N}^{\circ} 6^{\circ}$, de la Constitución Política, en tanto importa el poder de desarrollar los mandatos legales, por medio de una regulación pormenorizada, para así conseguir su concreción $»^{30}$.

Este nuevo estatus de las ordenanzas municipales (las “ordenanzas 2.0”), que se evidencia en la práctica municipal ya descrita, y en la jurisprudencia del Tribunal Constitucional, en orden a entenderlas como manifestación de la "potestad reglamentaria municipal" que "se asemeja a la potestad reglamentaria de ejecución del Presidente de la República", revela que ellas no sólo pueden infringir el marco competencial de las municipalidades sino que también vulnerar nuestros derechos fundamentales.

No cambia esta conclusión el hecho que la infracción de las ordenanzas municipales conlleve una sanción menor para el infractor (multa de hasta 5 unidades tributarias mensuales), pues el sólo hecho que ellas entren en vigor a pesar de presentar vicios de inconstitucionalidad y/o ilegalidad, incorporándose así al Ordenamiento Jurídico, constituye, a nuestro juicio, un grave atentado al Estado de Derecho, que preciso es oportunamente evitar o corregir.

Por tanto, si hoy las ordenanzas municipales están reglando materias propias de la ley, o bien son análogas al reglamento, estimamos necesario que el control preventivo al que estén sometidas sea análogo al de éstos.

\section{El control de las ordenanzas municipales}

\section{(A). Formas de control de las ordenanzas municipales}

Las formas en las que el control de las ordenanzas municipalidades tiene lugar, son las que siguen:

Control de legalidad preventivo. Tiene lugar respecto de un proyecto de ordenanza municipal, y entendemos por tal todo aquel que, haya sido o no aprobado por el concejo, aún no ha entrado en vigor (lo que acontece, por regla general, una vez que ha sido publicada «en los sistemas electrónicos o digitales de que disponga la municipalidad» $\left.{ }^{31}\right)$.

30 Sentencia del Tribunal Constitucional Rol No 3.093 , considerando $5{ }^{\circ}$.

31 Artículo ı2, inciso final, de la Ley No 18.695 , Orgánica Constitucional de Municipalidades 
Este control lo realizan:

(i). El alcalde y el concejo, ya que es una facultad del alcalde con acuerdo del concejo aprobarlas $^{32}$; $\mathrm{y}$ «las autoridades y jefaturas, dentro del ámbito de su competencia y en los niveles que corresponda, ejercerán un control jerárquico permanente del funcionamiento de los organismos [...] de su dependencia. Este control se extenderá tanto a la eficiencia y eficacia en el cumplimiento de los fines y objetivos establecidos, como a la legalidad y oportunidad de las actuaciones» ${ }^{33}$.

(ii). La Unidad de Control municipal ${ }^{34}$. Estimamos que este control, a la luz de la práctica municipal, es más bien simbólico, pues esta Unidad no tiene la solidez institucional necesaria para contrarrestar el manifiesto voluntarismo de los alcaldes -y el concejo- en cuanto a la aprobación de ordenanzas municipales, a pesar de los vicios de inconstitucionalidad o ilegalidad que puedan tener.

En efecto, nos parece que la facultad de representación que el artículo 29, letra c), de la Ley No 18.695, Orgánica Constitucional de Municipalidades ${ }^{35}$ reconoce a esta Unidad, está referida sólo a "actos municipales" del alcalde, pues es a éste a quien debe representar -informando al concejo- y éste quien debe enmendarlo; y no a aquellos que son aprobados por el alcalde con acuerdo del concejo, como las ordenanzas municipales, pues en estos casos de nada sirve informar al concejo (ya que éste la ha aprobado) y el alcalde poco o nada puede hacer en orden a enmendarla (pues ha sido aprobada no sólo por él, sino que por él con acuerdo del concejo).

(iii). La Contraloría General de la República. Conforme señalábamos con anterioridad, por disposición legal ${ }^{36}$, las ordenanzas no están sometidas al trámite de la toma de razón.

32 Artículos 65, letra k), de la Ley N ${ }^{\text {I } 8.695, ~ O r g a ́ n i c a ~ C o n s t i t u c i o n a l ~ d e ~ M u n i c i p a l i d a d e s . ~}$

33 Artículo II, inciso $2^{\circ}$, de la Ley $\mathrm{N}^{\circ}$ 18.575, Orgánica Constitucional de Bases Generales de la Administración del Estado.

34 Artículo 29 de la Ley No 18.695 , Orgánica Constitucional de Municipalidades.

35 En efecto, conforme al artículo 29, letra c), de la Ley N ${ }^{\circ}$ I8.695, Orgánica Constitucional de Municipalidades: "A la unidad encargada del control le corresponderán las siguientes funciones: c) Representar al alcalde los actos municipales que estime ilegales, informando de ello al concejo, para cuyo objeto tendrá acceso a toda la información disponible. Dicha representación deberá efectuarse dentro de los diez días siguientes a aquel en que la unidad de control haya tomado conocimiento de los actos. Si el alcalde no tomare medidas administrativas con el objeto de enmendar el acto representado, la unidad de control deberá remitir dicha información a la Contraloría General de la República”.

36 En efecto, conforme al artículo 53 de la Ley N ${ }^{\circ}$ I8.695, Orgánica Constitucional de Municipali- 
Con todo, la Contraloría General de la República siempre cumple un rol indirecto en el procedimiento de creación de una ordenanza municipal. Éste se evidencia en la fuerza vinculante de su jurisprudencia administrativa sobre esta materia. En efecto, en atención a ello, las municipalidades, al momento de estudiar un proyecto de ordenanza municipal, no podrían sino que revisar y conformarse a esa jurisprudencia.

Así, por ejemplo, hasta antes que se atribuyera por ley ${ }^{37}$ a las municipalidades la potestad para autorizar el cierre de calles y pasajes, se entendió que ésta era implícita de la potestad de administración de bienes nacionales de uso público ${ }^{38}$, y es así como ellas comenzaron a reglar su ejercicio a través de ordenanzas municipales. Los criterios que estas ordenanzas contenían para resolver sobre la autorización o no del cierre de calles y pasajes, fue disímil. En este contexto, la Contraloría General de la República, al pronunciarse sobre la legalidad de muchas de ellas -especialmente a instancia de particulares- fue estableciendo ciertos criterios que debían observar las ordenanzas municipales en esta materia, mismos que luego consolidó en determinados dictámenes ${ }^{39}$. Pues bien, la observancia de esos criterios marcó entonces la diferencia entre las ordenanzas municipales que se ajustaban o no a Derecho.

Asimismo, le puede caber un rol directo. Ello acontece cuando el alcalde, como máxima autoridad de la municipalidad ${ }^{40}$, o uno o más concejales, en el marco del procedimiento de creación de una ordenanza municipal, le requieren pronunciamiento a la Contraloría

dades dispone que "las resoluciones que dicten las municipalidades estarán exentas del trámite de toma de razón, pero deberán registrarse en la Contraloría General de la República cuando afecten a funcionarios municipales".

37 Ley N ${ }^{\circ}$ 20.499, Regula el Cierre de Calles y Pasajes por Motivos de Seguridad Ciudadana (DO: 08/02/20II).

38 Artículo $^{\circ}$, letra c), de la Ley No 18.695 , Orgánica Constitucional de Municipalidades.

39 Cf.: los dictámenes de la Contraloría General de la República Nos $76 \cdot 554^{-2010,35 \cdot 702-2010,23.64^{2-}}$ 2010, 69.663-2009, 4.398-2004, II.42I-2000. En lo medular, sostuvo que "las municipalidades se encuentran facultadas para autorizar el cierre, únicamente, de calles y pasajes de una sola entrada o salida, o pasajes peatonales, excepto cuando estas calles o pasajes converjan en una avenida o calle principal y siempre que ello no implique un detrimento importante al uso común de dichos bienes, ni se afecte gravemente los derechos constitucionales a los que se refiere el dictamen en estudio, no sólo de sus residentes, sino que de cualquier persona, debiendo en cada caso el municipio aplicar el principio de la racionalidad, basándose en un criterio jurídico de interés superior, debidamente ponderado y fundado en estudios técnicos" (Dictamen de la Contraloría General de la República No $38.149^{-2000}$ ).

40 Artículo 56 de la Ley No 18.695 , Orgánica Constitucional de Municipalidades. 
General de la República sobre la legalidad del proyecto de ordenanza municipal ${ }^{2142}$. Este proceder nos parece muy adecuado por cuanto un eventual dictamen favorable de aquélla en relación al proyecto, otorga a la municipalidad certeza sobre su legalidad.

La Contraloría General de la República ve con beneplácito este proceder, y en efecto cuando se le ha solicitado, ésta ha señalado que «si bien el documento aludido no está afecto a trámite ante este Organismo de Control, se ha estimado pertinente, en ejercicio de las atribuciones que le confieren los artículos $1^{\circ}$ y $6^{\circ}$, entre otros, de la Ley $\mathrm{N}^{\circ} 10.336$, sobre Organización y Atribuciones de la Contraloría General de la República, y 52 de la Ley N ${ }^{\circ}$ 18.695, Orgánica Constitucional de Municipalidades, efectuar algunas consideraciones en relación con el contenido de aquél»»33.

Control de legalidad represivo. Este tiene lugar a instancia de un particular. Es posible distinguir:

(i). Control jurisdiccional. Este tiene lugar mediante el ejercicio de acciones tales como el reclamo de ilegalidad municipal ${ }^{44}$, la nulidad de Derecho Público ${ }^{45}$, el recurso de protección ${ }^{46}$, el amparo económico ${ }^{47}$ y la acción de no discriminación arbitraria ${ }^{28}$.

41 Artículos $6^{\circ}$ y $9^{\circ}$ de la Ley $\mathrm{N}^{\circ}$ 10.336. Cf.: el dictamen de la Contraloría General de la República $\mathrm{N}^{\mathrm{o}} 2 \mathrm{I}_{4} \cdot \mathrm{I}_{4} 20 \mathrm{I} 5$.

42 Esta forma de proceder se advierte, por ejemplo, en los dictámenes de la Contraloría General de la República No s 2886-2010 у г6.506-2018. Este último es expedido en razón de la solicitud de pronunciamiento sobre la legalidad del "proyecto de ordenanza municipal que regula la participación ciudadana” de la I. Municipalidad de Providencia, presentada por el concejal señor Manuel José Monckeberg Balmaceda.

Asimismo, ha procedido el alcalde de La Florida respecto del proyecto de ordenanza que prohibiría los reglamentos de copropiedad de edificios situados en la comuna que prohíban la tenencia de animales. Cf.: "La Florida será la primera comuna que impedirá reglamentos de edificios que prohíban tener mascotas”, en "emol.cl”. Link: https://www.emol.com/noticias/ Nacional/20I8/ıo/25/925095/La-Florida-sera-la-primera-comuna-que-eliminara-la-prohibicionde-tener-mascotas-en-departamentos.html

43 Dictamen de la Contraloría General de la República 2.886-2oıo.

44. Artículo I5I de la Ley No 18.695 , Orgánica Constitucional de Municipalidades.

45 Artículo $6^{\circ}$ y $7^{\circ}$ de la Constitución Política de la República.

46 Artículo 20 de la Constitución Política de la República.

47 Ley $\mathrm{N}^{\mathrm{O}}$ I8.97I, Establece el Recurso Especial que Indica.

48 Título II de la Ley $\mathrm{N}^{\mathrm{o}} 20.609$, Establece Medidas contra la Discriminación. 
De ellas, la más empleada en esta materia, por cierto, es el recurso de protección.

(ii). Control administrativo. Se evidencia cuando un particular requiere pronunciamiento a la Contraloría General de la República sobre la legalidad de una ordenanza municipal.

Salvo que se trate de un asunto litigioso, en los términos del artículo $6^{\circ}$ de la Ley $\mathrm{N}^{\circ} 10.336$, Orgánica de la Contraloría General de la República (y es tal en la medida que haya sido judicializado), esta solicitud dará lugar a un dictamen que determinará si la respectiva ordenanza municipal se ajusta o no a Derecho; y en este último caso, dispondrá que la respectiva municipalidad adopte las medidas destinadas a dejarla, total o parcialmente, sin efecto. De esta forma, opera como un cuasi contencioso administrativo, en el que el dictamen hace las veces de sentencia. Con todo, cabe destacar que este dictamen tendrá fuerza vinculante respecto de las restantes municipalidades, razón por la cual aquéllas, en lo pertinente, igualmente, deberán ajustarse a sus términos.

Ponemos de relieve que la mayor parte de la jurisprudencia hallada sobre los límites de las ordenanzas municipales corresponde precisamente a la jurisprudencia administrativa de la Contraloría General de la República.

\section{(B). Criterios de control de las ordenanzas municipales}

Revisada la jurisprudencia constitucional, judicial y administrativa, podemos reconocer los siguientes criterios de control de las ordenanzas municipales. El principal es el principio de legalidad/juridicidad, y los otros no son más que concreciones particulares de éste.

\section{El principal criterio: principio de legalidad/juridicidad}

El principal criterio de control de las ordenanzas municipales, es el principio de legalidad/ juridicidad ${ }^{29}$.

En este sentido, la Contraloría General de la República ha observado que las ordenanzas municipales:

Son normas generales y obligatorias aplicables a la comunidad que pueden emitir los municipios en el ámbito local, regulando a través de estas, materias que se encuentran en la esfera de sus atribuciones. Enseguida, debe recordarse que [...] el ejercicio de tal potestad debe enmarcarse dentro del ordenamiento jurídico vigente, lo cual implica que por su intermedio no pueden establecerse mayores

49 Artículos $6^{\circ}$ y $7^{0}$ de la Constitución Política de la República y $2^{\circ}$ de la Ley ${ }^{\circ}{ }_{1} 8.575$, sobre Bases Generales de la Administración del Estado. 
requisitos o restricciones al desarrollo de las actividades económicas que aquellos que hubieren sido impuestos por la ley o por las normas dictadas por los órganos competentes, pues lo contrario significaría actuar en contravención a los artículos $6^{\circ}$ y $7^{\circ}$ de la Carta Fundamental, y $2^{\circ}$ de la Ley N ${ }^{\circ} 18.575$, Orgánica Constitucional de Bases Generales de la Administración del Estado, que consagran el principio de juridicidad ${ }^{50}$.

Con todo, cabe recordar que el principio de legalidad/juridicidad en relación a las ordenanzas municipales alude al menos a tres clases de normas (no sólo a la ley): (a). a la Constitución Política de la República; (b). a la ley, en general, y muy especialmente, a la Ley No 18.695, Orgánica Constitucional de Municipalidades; y (c). al reglamento.

En este sentido, el Tribunal Constitucional ha señalado que «la potestad normativa del municipio está subordinada, por una parte, a la Constitución y a la ley. Ello significa que está sujeta a dichas normas y no puede contradecirlas o invadir su ámbito propio de regulación. Por la otra, está subordinada a las normas que dicte el Presidente de la República en ejercicio de su potestad reglamentaria» ${ }^{51}$, y en otra oportunidad, muy especialmente que, «En todo caso, las ordenanzas no pueden contradecir los reglamentos del Presidente de la República» ${ }^{52}$.

\section{Otros criterios}

Otros criterios son:

(1). Las ordenanzas municipales sólo pueden regular materias comprendidas dentro de las funciones y atribuciones de las municipalidades, muy especialmente las que precisan los artículos $3^{\circ}, 4^{\circ}$ y $5^{\circ}$ de la Ley $N^{\circ} 18.695$, Orgánica Constitucional de Municipalidades. Esto por cuanto el ejercicio de sus potestades por parte de un órgano de la Administración, debe conformarse a su cometido institucional.

En este sentido, el Tribunal Constitucional ha observado que:

Las ordenanzas tienen un ámbito restringido de materias que pueden abordar. Estas dicen relación con las funciones que la Constitución y la ley les encargan

50 Dictamen de la Contraloría General de la República $\mathrm{N}^{\circ} 7 \cdot 368-20 \mathrm{I}_{4}$. En el mismo sentido, el dictamen $\mathrm{N}^{\circ} 6 .{ }_{4} \mathrm{I} 8-20 \mathrm{I} 3$.

51 Sentencia del Tribunal Constitucional Rol No ${ }^{\circ} \cdot 669$, considerando $47^{\circ}$.

52 Sentencia del Tribunal Constitucional Rol N ${ }^{\circ} 2.899$, considerando II $^{\circ}$. Esto también lo ha destacado la Contraloría General de la República. Así ha reprochado el hecho que una ordenanza municipal "contraviene el mencionado precepto reglamentario" (Dictamen de la Contraloría General de la República N $\left.13 \cdot 554^{-2013}\right)$. 
a los municipios (artículo 118 de la Constitución y Artículos $3^{\circ}$ y $4^{\circ}$ de la Ley Orgánica de Municipalidades). No obstante, cuando la Carta Fundamental le entrega la potestad normativa al Concejo Municipal, parece dar a entender que el único límite que tiene es de forma o de procedimiento, al señalar que la función normativa debe ejercerse "en la forma que determine la Ley Orgánica Constitucional respectiva” (artículo 119, inciso segundo). Pero dicho límite sustantivo emana de la propia naturaleza del municipio, cuya competencia es acotada a ciertos asuntos listados en la $1 \mathrm{ley}^{53}$.

Así, por ejemplo, por muy correcto y necesario que sea establecer mayores y mejores normas de protección para los animales de circos, las municipalidades no pueden hacerlo mediante ordenanzas municipales ni a través de ninguna otra clase de resolución municipal, ya que ello es del todo ajeno a sus funciones y atribuciones (antes bien corresponde a otros órganos de la Administración Servicio Agrícola y Ganadero). En este sentido, la Contraloría General de la República ha señalado que «es dable concluir que los municipios no están facultados para dictar una ordenanza que regule las condiciones de utilización de animales en los circos que se instalen en la respectiva comuna, así como tampoco agregar normas en tal sentido al ordenamiento local ya existente» ${ }^{54}$.

(2). Las ordenanzas municipales sólo deben contener normas propias del ámbito local. Esto ya que las normas propias del ámbito nacional se contienen en la ley y/o en el reglamento. De ello se sigue:

(i). Que las ordenanzas municipales no pueden invadir el ámbito normativo nacional. Si así lo hicieran, dado que la normativa que ellas contienen aplica sólo a la respectiva comuna, quebraría la coherencia interna del Ordenamiento Jurídico de nuestro Estado, singularizado como unitario por la Constitución Política de la República ${ }^{55}$; y configuraría, en los hechos, desde el punto normativo, uno federal.

En este sentido, una reciente sentencia de la Corte de Apelaciones de Santiago ${ }^{56}$, que se pronunció sobre el recurso de protección deducido por una persona en contra de la ordenanza municipal de la I. Municipalidad de Las Condes que prohíbe fumar en las plazas y parques públicos de la comuna que excede los términos de la Ley No 20.660, del Tabaco, en relación a este punto, sostuvo:

En el caso que se examina se afecta (la igualdad ante la ley -nota nuestra-) al establecer cargas más gravosas al recurrente, amenazando el goce efectivo de

\footnotetext{
53 Sentencia del Tribunal Constitucional Rol No 1.669 , considerando 49 .

54 Dictamen de la Contraloría General de la República N²3.800-20I5.

55 Artículo $3^{\circ}$, inciso ${ }^{\circ}$, de la Constitución Política de la República.

56 Sentencia de la Corte de Apelaciones de Santiago Rol No 82.527-20I8.
} 
su derecho a ser tratado de igual manera a quienes fuman en plazas de otras comunas del país, consagrando diferencias que no se encuentran presentes en la ley que regula la materia, desconociendo el igual trato que ha de darse a personas que se encuentran en hipótesis jurídicas iguales. [...] En definitiva con lo actuado por la recurrida a personas que se encuentran en la misma situación, les afectarían desiguales prohibiciones, quebrantándose de esa manera la coherencia interna del ordenamiento jurídico, al establecer restricciones que exceden el sentido de la regulación legal.

(ii). Que los reglamentos no pueden invadir el ámbito normativo local, que es propio de las ordenanzas municipales. Esto deberá ser controlado por la Contraloría General de la República al momento de efectuar la toma de razón de los mismos.

En este sentido, la sentencia del Tribunal Constitucional Rol No 3.489 , sobre control preventivo de constitucionalidad de la actual Ley N ${ }^{0}$ 21.020, sobre Tenencia Responsable de Mascotas y Animales de Compañía (coloquialmente conocida como "Ley Cholito"), contiene la prevención de los ministros señor Aróstica, señora Brahm y señor Letelier, que a propósito de la relación reglamento-ordenanza, señaló que «corresponderá a la Contraloría General de la República, en el trámite de toma de razón, verificar que este reglamento presidencial solamente cubra aspectos básicos a nivel nacional, dejando suficiente espacio para que en este orden de asuntos pueda tener lugar la potestad normativa municipal» ${ }^{57}$.

(3). En relación a las restricciones o limitaciones establecidas por ley y especificadas a través de un decreto (ya sea reglamentario o no), a nivel nacional, las ordenanzas municipales no pueden establecer estándares más estrictos, a nivel local.

Así, por ejemplo, una ordenanza municipal sobre ruidos no puede establecer niveles de emisión permitidos más estrictos que los fijados por el Presidente de la República mediante el respectivo decreto. En este sentido la Contraloría General de la República ha observado que «una ordenanza municipal no puede contravenir lo establecido en la respectiva norma de emisión. De este modo, no corresponde que en virtud de lo dispuesto en la ordenanza municipal en examen, una persona pueda ser sancionada a pesar de dar cumplimiento a los parámetros fijados por el aludido decreto $\mathrm{N}^{\circ} 38$, de 2011» ${ }^{58}$.

Del mismo modo, respecto de una ordenanza municipal sobre protección de humedales, que daba tal carácter y protección a sectores de la comuna que no lo tenían conforme a las normas legales y reglamentarias pertinentes, la Contraloría General de la República sostuvo que «no procede definir el ámbito de aplicación de la ordenanza en estudio en

57 Sentencia del Tribunal Constitucional Rol N ${ }^{\circ} 3 \cdot 489$ (prevención de los ministros señor Aróstica, señora Brahm y señor Letelier, considerando $\left.{ }_{4}^{\circ}\right)$.

58 Dictamen de la Contraloría General de la República Nº $26.560-2016$. 
términos tan amplios que sugieran que dicho instrumento ampara no sólo aquellas zonas declaradas prioritarias de conservación por la autoridad ambiental, o los sitios Ramsar, sino que establece nuevos sectores protegidos y limitaciones al dominio, al margen de la regulación legal y reglamentaria» ${ }^{59}$.

(4). Las ordenanzas municipales no pueden interpretar la ley. Ello por cuanto la potestad en cuya virtud las ordenanzas municipales son dictadas por las municipalidades es normativa, conforme se ha señalado, y no interpretativa. Esta última potestad (la potestad interpretativa en sede administrativa de la ley) ha sido atribuida por la ley excepcionalmente a algunos órganos de la Administración, y en relación a materias muy específicas, tales como, por ejemplo, la Contraloría General de la República, la Dirección del Trabajo, la Superintendencia de Casinos de Juego, etcétera, y entre los cuales no se cuentan las municipalidades.

Así, por ejemplo, la Contraloría General de la República, a propósito de una ordenanza sobre no discriminación arbitraria, sostuvo que la respectiva municipalidad no podía innovar en cuanto al concepto de discriminación arbitraria que otorga la Ley N $\mathrm{N}^{0} 20.609$, Establece Medidas Contra la Discriminación. Al efecto señaló que:

En la ordenanza que nos ocupa la determinación de que una actuación vulneró o no la dignidad de alguna persona o de un grupo de personas, en razón de su raza o etnia, la nacionalidad, la situación socioeconómica, el idioma, la ideología u opinión política, la religión o creencia, la sindicación o participación en organizaciones gremiales o la falta de ellas, el sexo, la orientación sexual, la identidad de género, el estado civil, la edad, la filiación, la apariencia personal y la enfermedad o discapacidad, se encuentra entregada a la ponderación que de ello realice el municipio, debiendo ajustarse a las disposiciones que establece la ley y que le entrega dicha definición a los tribunales de justicia ${ }^{60}$.

(5). Las materias reguladas por las ordenanzas municipales (o aspectos de éstas) no pueden estar comprendidas dentro de las competencias de otros órganos de la Administración.

Con todo, si así fuera, y tales materias están igualmente comprendidas dentro de las funciones y atribuciones de las municipalidades (lo que puede suscitarse muy especialmente con las denominadas funciones compartidas ${ }^{61}$ ), las ordenanzas no pueden sino estar en correspondencia con el ejercicio que dicho órgano ha efectuado de sus competencias, en razón de los principios de legalidad/juridicidad y de coordinación ${ }^{62}$.

59 Dictamen de la Contraloría General de la República No 276 -2org.

60 Dictamen de la Contraloría General de la República Nº 3 I.968-20I8.

61 Artículo $4^{\circ}$ de la Ley Nº 18.695 , Orgánica Constitucional de Municipalidades.

62 Artículo $5^{\circ}$, inciso $2^{\circ}$, de la Ley N ${ }^{\circ}$ 8. 575 , Orgánica Constitucional de Bases Generales de la Administración del Estado. 
Así, por ejemplo, respecto de una ordenanza municipal que prohibía la circulación de sustancias peligrosas en zona urbana de la comuna, la Contraloría General de la República sostuvo que las materias de tránsito público correspondían ser reguladas por el Ministerio de Transportes y Telecomunicaciones, «correspondiéndole a las Municipalidades sólo la de aplicar las disposiciones que emanen de dicha autoridad, o bien que se encuentren contenidas en la legislación. De lo anterior, se desprende que la implementación de una medida como [...] prohibir la circulación de sustancias peligrosas por el área urbana de la ciudad de Calama, requiere que el Ministerio de Transportes y Telecomunicaciones la disponga en forma previa a su aplicación -lo que no ha ocurrido en el caso en estudio-, sin perjuicio de la posterior participación de la municipalidad dentro de la esfera de sus atribuciones» ${ }^{63}$.

Asimismo, respecto de una ordenanza municipal que regulaba un sector de comuna como zona típica, sin haber sido formalmente declarada, la Contraloría General de la República sostuvo que:

La emisión de la referida Ordenanza ha significado, por una parte, interferir en atribuciones del Consejo de Monumentos Nacionales las que dicen relación con la aprobación de instructivos de intervención, tendientes a que las obras que se ejecuten en Zonas Típicas o Pintorescas guarden relación con el estilo arquitectónico general de la zona [...] A su vez, se ha vulnerado el artículo $5^{\circ}$ de la Ley N 18.575, Orgánica Constitucional de Bases Generales de la Administración del Estado, conforme al cual los órganos de la Administración del Estado deberán cumplir sus cometidos coordinadamente y propender a la unidad de acción, evitando la duplicación o interferencia de funciones ${ }^{64}$.

(6). Las ordenanzas municipales no pueden otorgar a las municipalidades o a otros órganos de la Administración nuevas funciones o atribuciones, ya que esto corresponde exclusivamente a la ley.

Así, por ejemplo, una ordenanza municipal no puede otorgar a una municipalidad como nueva función o atribución el imponer deberes a los padres respecto de sus hijos escolares como, por ejemplo, el deber de enviarlos al colegio. En este sentido, la Contraloría General de la República ha señalado que «una ordenanza municipal no puede conferir funciones y atribuciones a un municipio, como sucede en la especie, pues el instrumento idóneo para ello, de acuerdo al Artículo 118 de la Constitución Política, es una ley orgánica constitucional» ${ }^{65}$.

\footnotetext{
63 Dictamen de la Contraloría General de la República Nº 66.234-2009

64 Dictamen de la Contraloría General de la República Nº64.227-2009.

65 Dictamen de la Contraloría General de la República Nº $59 \cdot 40$-20Ir.
} 
Del mismo modo, respecto de una ordenanza sobre no discriminación arbitraria, que otorgaba potestad fiscalizadora al respecto a Carabineros de Chile, la Contraloría General de la República sostuvo que «no se advierte el fundamento legal que habilite al órgano comunal para ello, sin perjuicio de los convenios que esas instituciones puedan celebrar en aplicación del principio de coordinación de la Administración del Estado» ${ }^{66}$.

(7). Las ordenanzas municipales no pueden traspasar a otros órganos de la Administración o a particulares, las funciones y atribuciones que la ley ha otorgado a las municipalidades, más aún si éstas son privativas ${ }^{67} \mathrm{o}$ esenciales ${ }^{68}$.

Así, por ejemplo, una ordenanza municipal no puede imponer a los vecinos el deber de mantener limpios los bienes nacionales de uso público aledaños a sus propiedades, regar los árboles o el césped que se hallen en ese espacio, etcétera, pues ello se halla comprendido dentro de la función esencial de las municipales de administración de los bienes nacionales de uso público existentes en la comuna ${ }^{69}$. En este sentido, la Contraloría General de la República ha señalado que «es una función propia y esencial de estos (los municipios -nota nuestra-), lo que implica, por una parte, que no puede ser desarrollada con la participación de otros órganos de la Administración del Estado y, por otra, que no puede ser traspasada a los vecinos de la comuna, correspondiéndole su cumplimiento de manera exclusiva y excluyente» ${ }^{70}$.

(8). Las ordenanzas municipales no pueden prohibir actividades que están permitidas por la ley.

Conforme a este criterio, la Contraloría General de la República declaró la ilegalidad de una ordenanza municipal que prohibió el rodeo, pues «no procede que mediante una ordenanza municipal se prohíba el ejercicio de una actividad deportiva reconocida por el ordenamiento jurídico, como acontece con el rodeo, ya que ello significaría una discriminación arbitraria y una contravención al principio de juridicidad» ${ }^{71}$, y de las ordenanzas municipales que prohibieron el uso de bolsas de plástico ${ }^{72}$, pues «no es posible que a

66 Dictamen de la Contraloría General de la República Nº 3 I.968-20I8.

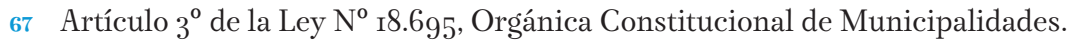

68 Artículo $5^{0}$ de la Ley Nº I8.695, Orgánica Constitucional de Municipalidades.

69 Artículo $5^{\circ}$, letra c), de la Ley No 18.695 , Orgánica Constitucional de Municipalidades.

70 Dictamen de la Contraloría General de la República No $85 \cdot 156-2013$.

71 Dictamen de la Contraloría General de la República Nº Io.I9I-20I8.

72 Con anterioridad a la Ley $\mathrm{N}^{\mathrm{o}}$ 2I.100, Prohíbe la Entrega de Bolsas de Plástico de Comercio en Todo el Territorio Nacional. 
través de una ordenanza se afecte, mediante una prohibición, el derecho a desarrollar una actividad económica, que asegura el Artículo 19, $\mathrm{N}^{\circ} 21^{\circ}$, de la Constitución Política» ${ }^{73}$.

(9). Las ordenanzas municipales no pueden establecer más requisitos o restricciones para el desarrollo de actividades económicas que aquellas impuestas por la Constitución Política de la República y las leyes ${ }^{74}$.

Conforme a este criterio, la Contraloría General de la República declaró la ilegalidad de las ordenanzas que, a propósito de los locales comerciales que explotan máquinas de destreza, les estableció distancias mínimas respecto de los establecimientos educacionales y especiales condiciones en cuanto a baños, aireación, aislamientos de ruido, etcétera, ya que, en cuanto a lo primero, «éstas (las ordenanzas -nota nuestra-) en ningún caso pueden establecer mayores requisitos o restricciones para el desarrollo de las actividades económicas, que aquellas que han sido impuestas por la Constitución Política y las leyes [...] la fijación de distanciamientos mínimos a los locales comerciales de que se trata en relación a otro tipo de establecimientos, importa una restricción especial al desarrollo de una actividad económica que vulnera tanto la garantía constitucional antes referida (artículo 19, No 21 nota nuestra) $»^{75}$, y en cuanto a lo segundo, ya que «no corresponde que mediante este tipo de cuerpos normativos se regulen materias propias de la Ley General de Urbanismo y Construcciones o de su ordenanza u otros cuerpos normativos, y se remitan o reproduzcan sus disposiciones, apartándose, por lo demás, en algunos aspectos de aquéllas» ${ }^{76}$.

Del mismo modo, una ordenanza municipal no puede establecer el deber de soterrar el cableado de telecomunicaciones, a no ser que la respectiva municipalidad solvente a los titulares del servicio el costo que ello importa. En este sentido, la Contraloría General de la República ha dictaminado que «el titular de un servicio de telecomunicaciones puede optar por tender o cruzar líneas aéreas o soterrarlas, no pudiendo los municipios disponer que su canalización sea sólo subterráneamente ya que ello restringiría el derecho de opción que otorga el artículo 18 de la Ley $N^{\circ} 18.168$ a los concesionarios, a menos que tal canalización se verifique con fondos municipales, toda vez que sólo en ese caso no se lesiona el derecho del titular de la concesión que ha elegido una opción diferente» ${ }^{77}$.

(10). Las ordenanzas municipales no pueden ser arbitrarias, vale decir, no deben obedecer al mero capricho.

\footnotetext{
73 Dictamen de la Contraloría General de la República Nº 86.870-20I4.

74 Artículo I9, $\mathrm{N}^{\circ}$ 26, de la Constitución Política de la República.

75 Dictamen de la Contraloría General de la República N $45 \cdot 262-2013$.

76 Dictamen de la Contraloría General de la República N ${ }_{43}^{\circ} \odot 33^{-20 I 6}$ (confirma el dictamen $\mathrm{N}^{\circ}$ $\left.34 \cdot 267^{-2015}\right)$.

77 Dictamen de la Contraloría General de la República Nº 2.8II-20Ig.
} 
Al respecto cabe señalar que los Tribunales o la Contraloría General de la República, al efectuar el control de la motivación de una ordenanza municipal, podrá hacerlo a la luz del decreto alcaldicio que la contenga, mas como no es necesario que ella se contenga en éste, parece más pertinente hacerlo a la luz del acta de la sesión del concejo en la que fue aprobada.

Así, por ejemplo, respecto de una ordenanza municipal sobre zonificación y horarios de funcionamiento de establecimientos de expendio de bebidas alcohólicas, que fijó el horario para salones de baile entre las 19:00 horas y las 01:00 horas del día siguiente (y 02:00 horas la madrugada de los días viernes, sábado, domingo y festivos), la Corte de Apelaciones de Santiago, sostuvo que:

No se trata de una facultad discrecional de la que pueda hacer uso de manera automática el respectivo alcalde, sino que se trata de un acto que debe estar debidamente fundado, además de contar con el consentimiento motivado del respectivo concejo municipal [...] Que, tampoco aparece el debido fundamento de las actas de sesiones del concejo en relación a la exigencia legal, desde que ni el director jurídico ni el alcalde en la sesión se refirieron a algún caso concreto, lo que no se complementa en el acto reclamado o en el acta de las sesiones del concejo que supuestamente sirvieron de fundamento a aquél [...] Deficiencias todas que dejan a la ordenanza cuestionada como arbitraria e ilegal ${ }^{78}$.

Del mismo modo, respecto de una ordenanza municipal que prohibió la vagancia y mendicidad en bienes nacionales de uso público, la Corte de Apelaciones de Antofagasta, rechazando el recurso, sostuvo que «la motivación de la Ordenanza viene dada en su parte considerativa de la que se extrae que busca velar por la circulación expedita de vehículos en la vía pública, el resguardo de los espacios y bienes nacionales de uso público y salvaguardar la seguridad pública comunal, por lo que no existe una desviación del fin público, además de contar con la debida motivación problemática social que pretende solucionarse con la Ordenanza, por lo que no puede entenderse que ésta sea antojadiza o caprichosa» ${ }^{79}$.

(11). Asimismo, si las ordenanzas municipales establecen discriminaciones, éstas en caso alguno pueden ser arbitrarias ${ }^{80}$.

Así, por ejemplo, respecto de una ordenanza municipal que, a propósito de los locales comerciales que explotan máquinas de destreza, les estableció distancias mínimas res-

77 Sentencia de la Corte de Apelaciones de Santiago Rol Nº $19 \mathrm{I}^{-20 I 8 .}$

78 Sentencia de la Corte de Apelaciones de Antofagasta Rol No $2.988-2017$.

79 Artículos rg, $\mathrm{N}^{\mathrm{o}} \mathrm{s} 2$ y 2I, de la Constitución Política de la República, y I ${ }^{\mathrm{o}}$, inciso $2^{\mathrm{o}}$, de la Ley $\mathrm{N}^{\mathrm{o}}$ 20.609, Establece Medidas contra la Discriminación. 
pecto de establecimientos educacionales, la Contraloría General de la República sostuvo que ella contravenía la garantía «consagrada en el artículo 19, $\mathrm{N}^{\circ}$ 2, de la Ley Suprema, en cuanto asegura el derecho a que ni la ley ni autoridad alguna podrán establecer diferencias arbitrarias» ${ }^{81}$.

(12). Las ordenanzas municipales no pueden incurrir en el vicio de la desviación de fin o de poder.

Así, por ejemplo, en el caso que una municipalidad que modifica su ordenanza municipal de cobro de derechos, estableciendo el pago de derechos excesivos respecto de un nuevo servicio (publicidad con pantallas led en edificios privados), respecto del cual tiempo atrás un particular le solicitó los permisos correspondientes, y ésta nada resolvió, razón por la cual aquél reclamó ante la Secretaría Regional Ministerial de Vivienda y Urbanismo, la que finalmente ordenó a la municipalidad otorgarlos; es dable suponer que dicha modificación tuvo por finalidad el dificultar o impedir que este particular lleve a cabo este nuevo servicio, esto es, una desviación de fin o de poder. En efecto, la Corte Suprema sostuvo que «las circunstancias bajo las cuales se procedió a la modificación de la ordenanza y las expuestas en el mismo acto administrativo, permiten razonablemente presumir que el fin que tuvo a la vista la autoridad fue otro, que se vincula con la situación particular que afecta a la recurrente y a las acciones que ésta debió ejercer para lograr una respuesta de la Administración» ${ }^{82}$.

(13). Las ordenanzas municipales no pueden desnaturalizar instituciones propias del Derecho Administrativo. Esto acontecería, por ejemplo:

(i). Si una ordenanza municipal estableciera que los permisos municipales de ocupación de un bien nacional de uso público sólo pueden ser revocados como consecuencia del incumplimiento de sus deberes por parte del permisionario, en circunstancias que la Ley No 18.695 , Orgánica Constitucional de Municipalidades otorga al efecto una amplia potestad discrecional al alcalde ${ }^{83}$ y los caracteriza como esencialmente precarios ${ }^{84}$. En este sentido, la Corte Suprema ha sostenido que «la Municipalidad escogió la figura jurídica del permiso [...] y no obstante ello en los artículos 20 y 26 (de la ordenanza -nota nuestra-) estableció que éste se puede dejar sin efecto únicamente por incumplimiento de las obligaciones de la empresa respectiva, lo que resulta incongruente con su naturaleza precaria $»^{85}$.

\footnotetext{
81 Dictamen de la Contraloría General de la República N ${ }_{45}$.262-20I3.

82 Sentencia de la Corte Suprema Rol No $55 \cdot 119-2016$.

83 Artículo 63, letra g), de la Ley Nº I8.695, Orgánica Constitucional de Municipalidades.

84 Artículo 36 de la Ley No 18.695 , Orgánica Constitucional de Municipalidades.

85 Sentencia de la Corte Suprema Rol No $3 \cdot 605^{-2008}$.
} 
(ii). Si a través de una ordenanza de participación ciudadana, se estableciera que algunos mecanismos de participación, distintos al plebiscito comunal, son vinculantes para la respectiva municipalidad. En este sentido, la Contraloría General de la República ha señalado que «las municipalidades se encuentran facultadas para determinar, a través de ordenanzas, diversas modalidades de participación ciudadana, las que corresponden a medios de apoyo que en ningún caso son vinculantes para dichas entidades edilicias, a excepción de los plebiscitos comunales, regulados expresa y detalladamente en su misma ley orgánica constitucional» ${ }^{86}$.

(14). Las ordenanzas municipales no pueden establecer sanciones distintas a multa ni multas superiores a cinco unidades tributarias mensuales ${ }^{87}$.

Así, por ejemplo, una ordenanza municipal no puede contemplar la sanción de comiso. En este sentido, la Contraloría General de la República ha señalado que «no sólo resulta improcedente que las municipalidades, por intermedio de una ordenanza local, establezcan castigos a ciertas conductas o ilícitos, no previstos legalmente, pues carecen de facultades para ello, sino que, además, en la situación de la especie, es la propia ley la que ya ha determinado la sanción que corresponde aplicar, esto es, la multa, por lo que no se ajusta a derecho que se imponga, por vía reǵlamentaria, una pena distinta o accesoria a la misma» ${ }^{88}$.

\section{Conclusión: propuestas de mejoras al control de las ordenanzas municipales, especialmente el preventivo}

A la luz de lo señalado precedentemente, podemos observar que los criterios de control de las ordenanzas municipales son variados y, en general, óptimos. Mas el problema radica en que ellos operan esencialmente en forma represiva, dado que su control de legalidad preventivo es prácticamente inexistente.

Por ello, y dado que las ordenanzas municipales hoy son potencialmente lesivas de derechos fundamentales, y que el Tribunal Constitucional las ha entendido análogas a la potestad reglamentaria, aunque en el plano local, estimamos que es necesario que se introduzcan mejoras en el control de legalidad preventivo al que están sujetas.

\footnotetext{
86 Dictamen de la Contraloría General de la República Nº I6.506-20r8.

87 Sentencia de la Corte de Apelaciones de Santiago Rol N ${ }^{\mathrm{o}} 3^{\mathrm{I}-20 \mathrm{I}}$.

88 Dictamen de la Contraloría General de la República N ${ }^{\circ}$ 54.966-2or3. En el mismo sentido, el dictamen $\mathrm{N}^{\mathrm{o}}$ I6.418-20I3.
} 


\section{Al efecto proponemos:}

En lo inmediato, promover que los alcaldes o concejales efectúen consultas a la Contraloría General de la República sobre la legalidad de los proyectos de ordenanzas que estudien, antes de que entren en vigor, ya sea antes o después de su aprobación por el concejo municipal. Esta práctica incluso puede ser formalizada a través de convenios de colaboración inter-orgánica entre municipalidades y la Contraloría General de la República.

Y en lo mediato, que las ordenanzas municipales queden sometidas al trámite de toma de razón; y dado que la exclusión de dicho trámite ha sido establecida por disposición legal expresa ${ }^{89}$, preciso es que ésta se modifique en este sentido, tal como ha acontecido recientemente con el reglamento interno que fija la planta del personal municipal, a través de la Ley $\mathrm{N}^{0} 20.922^{90}$. Además, de esta forma las ordenanzas municipales quedarían sometidas al mismo control preventivo de legalidad al que lo están las normas cuya naturaleza jurídica nos parece es la más cercana a la de ellas en el sistema de fuentes del Derecho Administrativo, esto es, las normas de carácter general que pueden dictar los Gobiernos Regionales ${ }^{91}$.

89 Artículo 53 de la Ley Nº I8.695, Orgánica Constitucional de Municipalidades.

90 En efecto, conforme al nuevo artículo 49 bis, incisos $\mathrm{I}^{\circ}$ y $2^{\circ}$, de la Ley $\mathrm{N}^{\mathrm{o}}$ I8.695, Orgánica Constitucional de Municipalidades:

"Artículo 49 bis. Los alcaldes, a través de un reglamento municipal, podrán fijar o modificar las plantas del personal de las municipalidades, estableciendo el número de cargos para cada planta y fijar sus grados, de conformidad al Título II del decreto Ley $\mathrm{N}^{\circ} 3 \cdot 55^{\mathrm{I}}$, del Ministerio de Hacienda, promulgado el año ig8o y publicado el año ig8I.

Sin perjuicio de lo dispuesto en el artículo 53, el reglamento que se dicte ejerciendo la potestad reconocida en el inciso anterior estará sometido al trámite de toma de razón ante la Contraloría General de la República y se publicará en el Diario Oficial."

91 Recordemos que, conforme a lo previsto en el artículo I6, letra h), de la Ley No I9.I75, Orgánica Constitucional Sobre Gobierno y Administración Regional, serán funciones generales del Gobierno Regional: “h) Dictar normas de carácter general para regular las materias de su competencia, con sujeción a las disposiciones legales y a los decretos supremos reglamentarios, las que estarán sujetas al trámite de toma de razón por parte de la Contraloría General de la República y se publicarán en el Diario Oficial”. 


\section{BIBLIOGRAFÍA}

- Chible Villadangos, María José. "La idoneidad de las ordenanzas municipales para satisfacer las necesidades públicas y las exigencias ciudadanas". Memoria de prueba para optar al grado de Licenciado en Ciencias Jurídicas y Sociales. Santiago: Facultad de Derecho Universidad de Chile, 2014.

- Baeza Fernández, Rodrigo. Manual jurídico municipal. Santiago: Corporación de Promoción Universitaria, 2004.

- Fernández Richard, José. Derecho Municipal Chileno. Santiago: Editorial Jurídica de Chile, 2003.

- García Fernández, Javier. El origen del municipio constitucional. Madrid: Instituto de Estudios de la Administración Local, 1983.

- Huidobro Salas, Ramón. Tratado de Derecho Administrativo, Derecho y Administración Comunal. Santiago: Editorial Legal Publishing, 2010.

- Román Cordero, Cristian. "Dictámenes de la Contraloría General de la República y acción declarativa de mera certeza”. Sentencias Destacadas 2017, Libertad y Desarrollo, Santiago (2018): 389-434.

- Román Cordero, Cristian. "Ordenanzas municipales: límites y control”, Teoría Política y Constitucional. Libro en homenaje al profesor Ismael Bustos. Santiago: Asociación Chilena de Derecho Constitucional, Editorial Jurídica de Chile (2017): 183-201.

- Román Cordero, Cristian (2016). "Ordenanzas municipales y tenencia responsable de mascotas”, Revista de Derecho y Humanidades, $n^{\circ} 27$ (2016): 13-36.

- Román Cordero, Cristian. "El "decálogo" de las ordenanzas municipales”. Revista Jurídica Municipal, Asociación de Municipalidades de Chile, Tercera Edición (Mayo 2019): 5-6.

- Silva Cimma, Enrique. Derecho Administrativo Chileno y Comparado. Introducción y fuentes. $5^{\text {a }}$ edición. Santiago: Editorial Jurídica de Chile, 2009. 


\section{JURISPRUDENCIA CITADA}

\section{SENTENCIAS DEL TRIBUNAL CONSTITUCIONAL}

Sentencia del Tribunal Constitucional Rol No 3.489.

Sentencia del Tribunal Constitucional Rol No 3.093.

Sentencia del Tribunal Constitucional Rol No 2.899 .

Sentencia del Tribunal Constitucional Rol Nº 1.669 .

Sentencia del Tribunal Constitucional Rol Nº 1.457.

Sentencia del Tribunal Constitucional Rol Nº 1.268.

\section{SENTENCIAS DE LOS TRIBUNALES DE JUSTICIA}

Sentencia de la Corte Suprema Rol No 18.846-2018.

Sentencia de la Corte Suprema Rol No 55.119-2016.

Sentencia de la Corte Suprema Rol No 5.379-2012.

Sentencia de la Corte Suprema Rol No 3.605-2008.

Sentencia de la Corte de Apelaciones de Santiago Rol No 82.527-2018.

Sentencia de la Corte de Apelaciones de Santiago Rol No 31-2018.

Sentencia de la Corte de Apelaciones de Santiago Rol No 191-2018.

Sentencia de la Corte de Apelaciones de Antofagasta Rol No 2.988-2017.

\section{DICTÁMENES DE LA CONTRALORÍA GENERAL DE LA REPÚBLICA}

Dictamen de la Contraloría General de la República No 2.811-2019.

Dictamen de la Contraloría General de la República No 276-2019.

Dictamen de la Contraloría General de la República No 31.968-2018.

Dictamen de la Contraloría General de la República No 16.506-2018.

Dictamen de la Contraloría General de la República N 10.191-2018. 
Dictamen de la Contraloría General de la República No 7.329-2018

Dictamen de la Contraloría General de la República N 43.033-2016

Dictamen de la Contraloría General de la República No 26.560-2016.

Dictamen de la Contraloría General de la República Nº 34.267-2015.

Dictamen de la Contraloría General de la República No 23.800-2015.

Dictamen de la Contraloría General de la República No 86.870-2014.

Dictamen de la Contraloría General de la República No 70.127-2014

Dictamen de la Contraloría General de la República No 17.188-2014.

Dictamen de la Contraloría General de la República Nº 7.368-2014.

Dictamen de la Contraloría General de la República No 85.156-2013.

Dictamen de la Contraloría General de la República Nº 75.366-2013.

Dictamen de la Contraloría General de la República № 54.966-2013.

Dictamen de la Contraloría General de la República N 45.262-2013.

Dictamen de la Contraloría General de la República No 16.418-2013.

Dictamen de la Contraloría General de la República № 13.554-2013.

Dictamen de la Contraloría General de la República № 2.484-2013.

Dictamen de la Contraloría General de la República No 59.480-2011.

Dictamen de la Contraloría General de la República No 32.889-2011.

Dictamen de la Contraloría General de la República No 76.554-2010.

Dictamen de la Contraloría General de la República No 35.702-2010.

Dictamen de la Contraloría General de la República No 26.019-2010

Dictamen de la Contraloría General de la República No 23.642-2010.

Dictamen de la Contraloría General de la República No 2.886-2010.

Dictamen de la Contraloría General de la República Nº 69.663-2009.

Dictamen de la Contraloría General de la República No 66.234-2009

Dictamen de la Contraloría General de la República N 64.227-2009.

Dictamen de la Contraloría General de la República No 7.902-2009. 
Dictamen de la Contraloría General de la República No 4.398-2004.

Dictamen de la Contraloría General de la República No 38.149-2000.

Dictamen de la Contraloría General de la República Nº 11.421-2000.

\section{FUENTES NORMATIVAS}

Constitución Política de la República.

Ley N ${ }^{o}$ 21.100, Prohíbe la Entrega de Bolsas de Plástico de Comercio en Todo el Territorio Nacional.

Ley No 21.020, sobre Tenencia Responsable de Mascotas y Animales de Compañía.

Ley N ${ }^{0}$ 20.922, Modifica Disposiciones Aplicables a los Funcionarios Municipales y Entrega Nuevas Competencias a la Subsecretaría de Desarrollo Regional y Administrativo.

Ley No 20.609, Establece Medidas Contra la Discriminación.

Ley N ${ }^{0}$ 20.499, Regula el Cierre de Calles y Pasajes por Motivos de Seguridad Ciudadana.

Ley No 20.285, sobre Acceso a la Información Pública.

Ley No 19.175, Orgánica Constitucional Sobre Gobierno y Administración Regional.

Ley No 18.971, Establece Recurso Especial que Indica.

Ley No 18.695, Orgánica Constitucional de Municipalidades.

Ley No 18.575 , Orgánica Constitucional de Bases Generales de la Administración del Estado.

Ley N ${ }^{\circ} 10.336$, de Organización y Atribuciones de la Contraloría General de la República. 